\title{
To stratify complications of percutaneousnephrolithotomy (pcnl) in a single hospital by use of the modified clavien grading system
}

Limbu Y, Joshi R , Dangol UMS, Singh DR

Department of Surgery, Kathmandu Medical College Teaching Hospital, Sinamangal, Kathmandu

Correspondence : Yugal Limbu, Resident, Departmentof Surgery, Kathmandu Medical College Teaching Hospital

Email-yugallimbu21@gmail.com

\begin{abstract}
Introductoin - PCNL is relatively safe but evaluating its complication can be of importance so that we can better anticipate and act on it.

Purpose: To evaluate the complications of percutaneous nephrolithotomy (PCNL).

Materials and methods: We prospectively analyzed the patients who underwent conventional PCNL at KMCTH from March 2013 to July 2015. Eighty five cases with renal stones more than $1 \mathrm{~cm}$ and upper ureteric stones were included in the study. Patients with coagulation disorder were not included in this study. Ten patients who had PCNL converted to open procedureswere excluded in thestudy. Patients underwentPCNLin prone position. Pre-operative complete blood count, urine, ultrasound(USG), intravenous Urography (IVU) was done. CTIVU was also done in few cases. During the period of which Demographic data, stone free rate, hospital stay and complications were assessed.
\end{abstract}

Results: A total of 95 cases were enrolled for the study. Ten cases were excluded. There were 47 (55.29\%) were female and 38 (44.71\%) were male.Most of the patients had unilateral kidney stones(78.82\%).Mean size of the was $1.85 \mathrm{~cm}$.There were $38(44.70 \%)$ renal pelvi-ureteric junction(PUJ) stones out of 85 cases.Sub-costal approach for PCNL was carried out in 78 (91.77\%) patients. Mean operative time was 59.29 minutes with blood loss of $72.58 \mathrm{ml}$ and three patients needed blood transfusion. Twelve patients(14.11\%) experienced PCNL related complication. There was 1 mortality. Stone free rate was $91.76 \%(n-78)$.

Conclusion: PCNL is safe with acceptable complication rate and has an acceptable high stone free rate .

Key words:Intravenous Urography, Nephrostomy, Percutaneous Nephrolithotomy,Pelvi-ureteric junction,Ultrasonography. 